
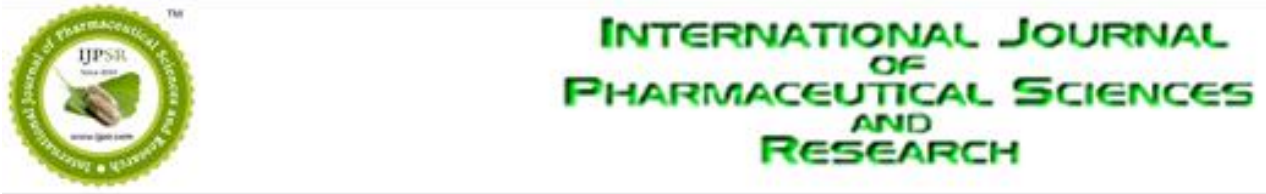

Received on 14 April, 2013; received in revised form, 10 June, 2013; accepted, 14 August, 2013; published 01 October, 2013

\title{
HPLC-UV METHOD DEVELOPMENT FOR ATORVASTATIN CALCIUM MICRO-EMULSION DETERMINATION IN RAT PLASMA AND ITS APPLICATION TO ELUCIDATE PHARMACOKINETIC BEHAVIOR AFTER ORAL ADMINISTRATION TO RATS
}

Liandong $\mathrm{Hu}^{* 1,2}$, Weihua Song ${ }^{1,2}$, Hailei Zhang ${ }^{1,2}$, Deliang $\mathrm{Gu}^{1,2}$

College of Pharmaceutical Sciences ${ }^{1}$, Hebei University, Baoding, China

Key Laboratory of Pharmaceutical Quality Control of Hebei Province ${ }^{2}$, Hebei University, Baoding, China

Keywords:

Atorvastatin calcium microemulsion, HPLC, Deproteinization,

UV detection, Rat plasma, Pharmacokinetics

Correspondence to Author:

\section{Liandong $\mathrm{Hu}$}

College of Pharmaceutical Sciences , Hebei University, Baoding, China

E-mail: hbupharm@126.com
ABSTRACT: A simple, rapid and validated high performance liquid chromatography (HPLC) method with UV detection for the quantification of atorvastatin Calcium microemulsions (ATC-MEs) in rat plasma was developed. The assay procedure involved chromatographic separation using a C-18 chromatographic column $(250 \mathrm{~mm} \times 4.6 \mathrm{~mm}$, i.d., $5 \mu \mathrm{m})$ and a mobile phase of methanol/water (containing $0.05 \%$ glacial acetic acid) $(70: 30, \mathrm{v} / \mathrm{v}) 1.0 \mathrm{~mL} / \mathrm{min}$ and detection wavelength of $248 \mathrm{~nm}$. Plasma sample $(200 \mu \mathrm{L})$ pretreatment was based on simple deproteinization by ethanol and centrifugation. The organic layer was evaporated under $\mathrm{N}_{2}$ gas, reconstituted with $200 \mu \mathrm{L}$ of mobile phase, and $20 \mu \mathrm{L}$ portions of reconstituted sample were injected onto the column. Calibration curve was linear ( $\mathrm{r} \geq 0.9854)$ from 0.1 to $50 \mathrm{mg} / \mathrm{L}$. Both intra- and inter-day assay precisions that are presented through RSD were lower than $12.4 \%$ for intra-day and lower than $12.5 \%$ for inter-day assessment. This method was omitting the use of expensive solid phase extraction and time consuming liquid extraction procedures. Moreover, the present method was successfully applied to study pharmacokinetic parameters of ATC-MEs after oral administration to healthy Sprague-Dawley rats. Pharmacokinetic parameters evaluated using the analysis method were $\mathrm{T}_{1 / 2} 2.77 \pm 1.06 \mathrm{~h}, \mathrm{~T}_{\max } 1.83 \pm 1.17 \mathrm{~h}, \mathrm{C}_{\max }$ $8.34 \pm 3.66 \mathrm{mg} / \mathrm{L}$ and $\mathrm{AUC}_{0-\infty} 22.07 \pm 5.44 \mathrm{mg} \cdot \mathrm{h} / \mathrm{L}$.
INTRODUCTION: Atorvastatin, a member of the drug class known as statins, is widely used as a synthetic lipid-lowering agent. It could stabilize plaque and prevent strokes through antiinflammatory and other mechanisms.

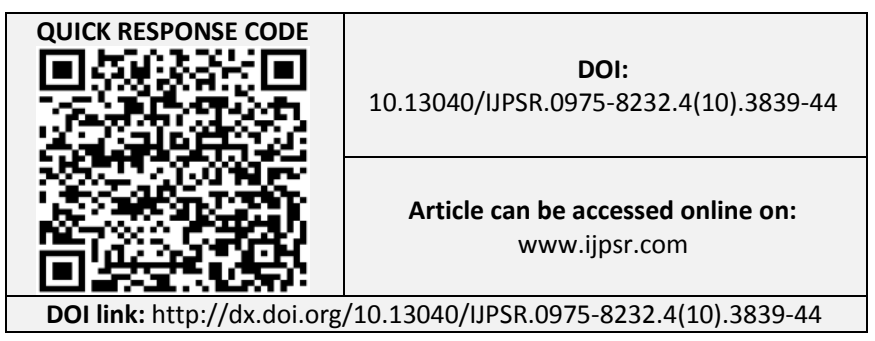

Like all statins, atorvastatin worked by inhibiting 3-hydroxy-3-methyl-glutaryl-coenzyme A (HMG$\mathrm{CoA}$ ) reductase, which was the rate-limiting step in the hepatic cholesterol biosynthesis ${ }^{1}$.

Atorvastatin calcium (ATC) is commonly used for the treatment of hypercholesterolemia, especially homozygous familial hypercholesterolemia, by inhibiting the synthesis of HMG-CoA reductase and cholesterol to increase the metabolism of LDLcholesterol. It was rapidly absorbed after oral administration, but the absolute bioavailability of it was approximately $14 \%$, which was due to low 
solubility, pre-systemic clearance in the gastrointestinal mucosa and/or hepatic first-pass metabolism $^{2,3}$.

Due to high utilization of ATC, several studies have been reported for its detection in different biological samples using various separation and detection techniques including high-performance liquid chromatography coupled to tandem mass spectroscopy (LC-MS) ${ }^{4-6}$, ultra high pressure liquid chromatography (UHPLC) ${ }^{7}$, and some other HPLC-UV methods ${ }^{8-11}$. However, these methods rely on quite similar approaches using internal standard; even in some of the literatures, there was no detailed description of the analytical procedures.

The present study described a new validated, simple, accurate, and normal-phase HPLC method for the determination of ATC in micro-emulsions and plasma and its application to pharmacokinetic studies in rats.

\section{EXPERIMENTAL:}

Reagents: Pure ATC was supplied by Zhejiang Neo-dongguang Pharm. Co., Ltd (Zhejiang, China). Labrafil M 1944 CS (1944 CS) was gifts from Gattefossé Co. (Shanghai, China). Cremophor EL was provided by Xietai Chemical Co. Ltd. (Shanghai, China). PEG 400 was purchased from Huadong Chemical Co. (Tianjin, China). Acetic acid was supplied from Kermel Chemical Co. Ltd. (Tianjin, China). Ethanol and acetonitrile were HPLC grade and supplied from Kermel Chemical Co. Ltd. (Tianjin, China).

Stock solutions (500 mg/ L) of ATC were subsequently diluted to prepare working standards with ethanol. Method validation samples were prepared by pipetting suitable amounts of ATC, and all stock solutions were kept at $4^{\circ} \mathrm{C}$.

Chromatographic apparatus and conditions: The samples were analyzed by HPLC which was equipped with a SPD-20A UV/VIS detector and LC-20AT pumps (Shimadzu, Kyoto, Japan). A C18 chromatographic column $(5 \mu \mathrm{m}, 250 \mathrm{~mm} \times 4.6$ $\mathrm{mm}$, Bonna-Agela Technologies, Inc., Wilmington, DE) was used at room temperature. The wavelength of the UV-detection was set at $248 \mathrm{~nm}$. Mixture of methanol/water (containing $0.05 \%$ glacial acetic acid) (70:30, v/v) was used as the mobile phase at a flow rate of $1.0 \mathrm{~mL} / \mathrm{min}$ for the in samples.

Plasma collection: Plasma of Healthy SpragueDawley rats was used in the experiments. The rats were housed in the conditions of constant temperature $\left(25 \pm 1{ }^{\circ} \mathrm{C}\right)$, provided with standard laboratory food and water. After $24 \mathrm{~h}$ of fasting, the rats were allowed to administer ATC-MEs (75 $\mathrm{mg} / \mathrm{kg}$, BW $)$. Blood samples $(0.5 \mathrm{ml})$ were collected containing heparin in tubes at $0,0.25$, $0.5,1,2,4,6,8$ and $12 \mathrm{~h}$ from the canthus. Then it was centrifuged at $4,000 \mathrm{rpm}$ for $15 \mathrm{~min}$. The supernatant was stored at $-20{ }^{\circ} \mathrm{C}$ until determined by HPLC method

Plasma pretreatment: $600 \mu \mathrm{l}$ of ethanol was spiked to $200 \mu \mathrm{l}$ of rat plasma and vortex-mixed for 5 min. To complete protein precipitation, the samples were left for $5 \mathrm{~min}$. The samples were subsequently centrifuged at 4,000 rpm for $15 \mathrm{~min}$, and $500 \mu \mathrm{l}$ of organic layer was transferred into a test tube. Collected organic layer extract was evaporated to dryness under $\mathrm{N}_{2}$ gas. The residue was reconstituted with $200 \mu \mathrm{l}$ mobile phase, and 20 $\mu l$ portions of reconstituted sample were injected onto the column.

Validation of the method: Calibration curves were prepared using plasma samples spiked with known concentrations of ATC (final concentrations in plasma were $0.1,0.2,0.5,2,10,25$ and 50 $\mathrm{mg} / \mathrm{L}$ ). The limits of detection (LOD) and quantitation (LOQ) were calculated as the peak height at a signal-to-noise (S/N) ratio of 3 and 10 , respectively. Intra- and inter-day assay precision, accuracy and recovery were assessed using rat plasma spiked with $0.5,10$ and $25 \mathrm{mg} / \mathrm{L}$ of ATC were used. Triplicate measurements for each standard concentration were performed.

The accuracy was calculated as found concentration/nominal concentration, while the recovery was calculated as peak height ratio of ATC in plasma/ peak height ratio of standard ATC in ethanol.

Application to pharmacokinetic study on rat: The study in vivo pharmacokinetic was performed in healthy Sprague-Dawley rats $(n=6$, weight 190 $230 \mathrm{~g})$. 
Blood sampling after oral administration of ATCMEs (75 mg/kg, BW) was held at $0,0.25,0.5,1,2$, $4,6,8$ and $12 \mathrm{~h}$ from the canthus. It was pretreated as mentioned earlier.

The concentrations of ATC in rat plasma were calculated from the corresponding calibration curve. The data analysis for calculating the pharmacokinetic parameters was performed by Microsoft Excel software. $\mathrm{K}$ was estimated by the linear regression of $\log \mathrm{C} /$ time profile (where $\log$ $\mathrm{C}$ is the log-normal transformed plasma concentration).

The terminal elimination half-life $\left(\mathrm{T}_{1 / 2}\right)$ was calculated by $\mathrm{T}_{1 / 2}=0.693 / \mathrm{K}$. Peak observed concentrations $\left(\mathrm{C}_{\max }\right)$ of drug and times to reach peak plasma concentration $\left(\mathrm{T}_{\max }\right)$ were determined from the individual plasma concentration-time curves.

The total area under the concentration-time curve (AUC) was calculated by the method of trapezoids. The area from time zero to infinity was calculated by $\mathrm{AUC}_{0-\infty}=\mathrm{AUC}_{0-\mathrm{t}}+\mathrm{Ct} / \mathrm{K}$. AUMC was the area under the first moment of the plasma concentration-time curve, calculated by AUMC ${ }_{0-\infty}$ $=\mathrm{AUMC}_{0-\mathrm{t}}+\mathrm{Ct} / \mathrm{K}$. Mean residence time was MRT, where MRT = AUMC/ AUC. The data were expressed as the mean \pm standard deviation (SD).

\section{RESULTS AND DISCUSSION:}

Sample preparation: The preparation of sample procedure consisted only of protein precipitation by the addition of ethanol to the plasma samples. Despite this simple procedure, it is more safety and convenient than other protein precipitation procedures such as the addition of acetonitrile ${ }^{6,9}$ and acetic ether ${ }^{8}$.

In our study, no internal standard was added, not only because it is not easy to find a molecule of polarity, similar molecular size and protein combinis in contrast with ATC, but also the usual internal standards, such as methaqualone 6 , indomethacin ${ }^{9}$, and diclofenac sodium solution ${ }^{8}$, must be refrained from using because it is quite possible present in unknown amounts in patient samples.
Furthermore, I.S. may add to the whole imprecision and inaccuracy of the process. It cannot be correct for extraction losses of ATC in the protein precipitation and may provide a false sense in the assay.

Chromatography: Under the described conditions, various mobile phases were assessed. Finally, the ratio of methanol and water (containing $0.05 \%$ glacial acetic acid) $(=70: 30, \mathrm{v} / \mathrm{v})$ provided the optimal separation of ATC at a retention time of $5.6 \mathrm{~min}$. For ATC-MEs treated rats, no interfering peaks were detected (see Fig. 1A).

ATC characters a very sensitive UV-absorption spectrum peak with absorption maxim at $248 \mathrm{~nm}$ (see Fig. 1B). These results accorded with the previously reported methods that are using detection wavelengths ranging from 200 to $210 \mathrm{~nm}$ 6-8. The HPLC assay was used to the following parameters, namely, specificity, linearity, limit of quantification (LOQ), limit of detection (LOD), precision, accuracy and recovery.
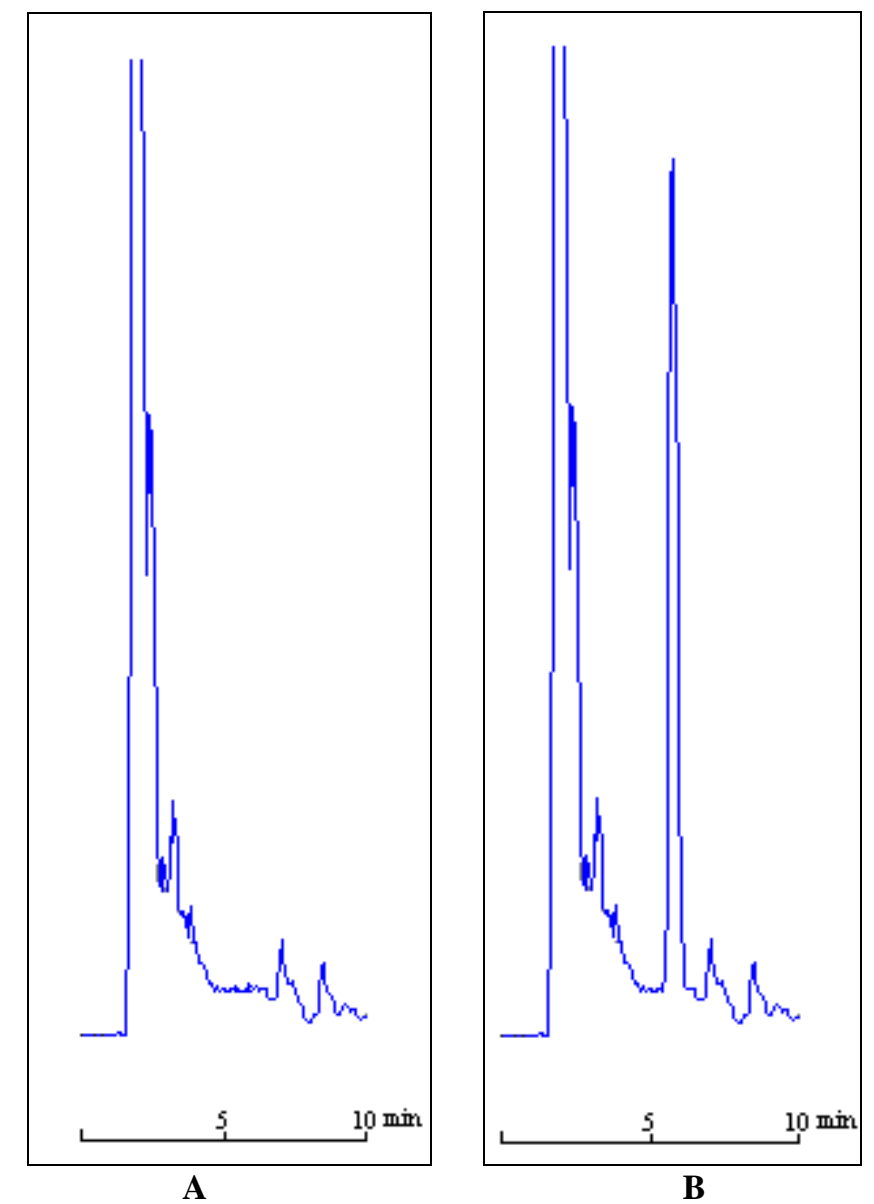

FIG. 1: CHROMATOGRAMS OF (A) BLACK PLASMA AND (B) SPIKED PLASMA WITH ATC 
Method validation: The calibration curve in rat plasma spiked with ATC was obtained by plotting the peak with a replicate of three times. The concentration of the calibration samples were in the range of $0.1-50 \mathrm{mg} / \mathrm{L}$ with a correlation coefficient of $(r=0.9854)$. The limit of quantification (LOQ) was set to the lower limit of the calibration range, i.e. $0.05 \mathrm{mg} / \mathrm{L}$. The limit of detection (LOD) was found to be about $0.02 \mathrm{mg} / \mathrm{L}$ $(\mathrm{S} / \mathrm{N}$ ratio 3$)$. In Table 1 , the precision and accuracy data for the intra-day and inter-day validation measurements are summarized. The intra-day assay precision (relative standard deviation, RSDs) was $12.4 \%(0.5 \mathrm{mg} / \mathrm{L}), 5.0 \%$ (10 $\mathrm{mg} / \mathrm{L})$ and $2.2 \%(25 \mathrm{mg} / \mathrm{L})$. Inter-day assay precision (RSDs) was $12.5 \%(0.5 \mathrm{mg} / \mathrm{L}), 5.2 \%$ (10 $\mathrm{mg} / \mathrm{L})$ and $3.2 \%(25 \mathrm{mg} / \mathrm{L})$. The recoveries were ranging from 96.5 to $101.1 \%$, and accuracies ranging from 89.7 to $97.9 \%$ (Table 2). The guidelines for the international conference of harmonization $(\mathrm{ICH})$ were utilized for the validation of this method ${ }^{13}$.

\section{TABLE 1: CALIBRATION RANGE AND LIMITS OF DETECTION AND QUANTITATION OF ATC IN SPIKED} RAT PLASMA

\begin{tabular}{ccccc}
\hline Calibration range $(\mathbf{m g} / \mathbf{L})$ & $\mathbf{r}^{\mathbf{a}}$ & Regression equation $^{\mathbf{b}, \mathbf{c}}$ & LOD $^{\mathbf{d}}, \mathbf{n g} / \mathbf{m l}$ & LOQ $^{\mathbf{d}}, \mathbf{n g} / \mathbf{m l}$ \\
\hline $0.1-50$ & 0.9854 & $y=21350.7 \mathrm{x}+22082.6$ & 20 & 50 \\
\hline
\end{tabular}

${ }^{\mathrm{a}}$ Correlation coefficient; ${ }^{\mathrm{b}} \mathrm{y}=$ peak height of ATC; $\mathrm{x}=$ sample concentration, $\mathrm{ng} / \mathrm{ml} ;{ }^{\mathrm{c}}$ Slope and $\mathrm{y}$-intercept were expressed as mean $\pm \mathrm{SD}(\mathrm{n}=3) ;{ }^{\mathrm{d}}$ Limits of detection and quantitation at $\mathrm{S} / \mathrm{N}=3$ and 10

TABLE 2: METHOD PRECISION, RECOVERY AND ACCURACY OF RAT PLASMA SPIKED WITH ATC

\begin{tabular}{|c|c|c|c|c|}
\hline \multirow{2}{*}{ Added ATC, mg/ L } & \multicolumn{2}{|c|}{ Precision \% $\left(\right.$ RSD) ${ }^{a}(n=3)$} & \multirow{2}{*}{ Recovery \% } & \multirow{2}{*}{ Accuracy $\%^{b}$} \\
\hline & Intra-day & Inter-day & & \\
\hline 0.5 & 12.4 & 12.5 & 96.5 & 89.7 \\
\hline 10 & 5.0 & 5.2 & 101.1 & 97.9 \\
\hline 25 & 2.2 & 3.2 & 99.9 & 95.6 \\
\hline
\end{tabular}

${ }^{a}$ Relative standard deviation

${ }^{\mathrm{b}}$ Accuracy $\%=($ found concentration/nominal concentration $) \times 100(\mathrm{n}=3)$

Pharmacokinetics of ATC in rats: The method was applied on Sprague-Dawley rats to evaluate the pharmacokinetic behavior after oral administration of ATC. Several sampling schedules were assessed till we achieved the most appropriate duration of detection. A dose of $75 \mathrm{mg} / \mathrm{kg}$ was used for treatment though it represented relatively higher plasma concentration than that of therapeutic in human, but same time it satisfied the proposed goal of pharmacokinetic determination. Fig. 2 shows plasma concentration-time curve of ATC after oral administration.

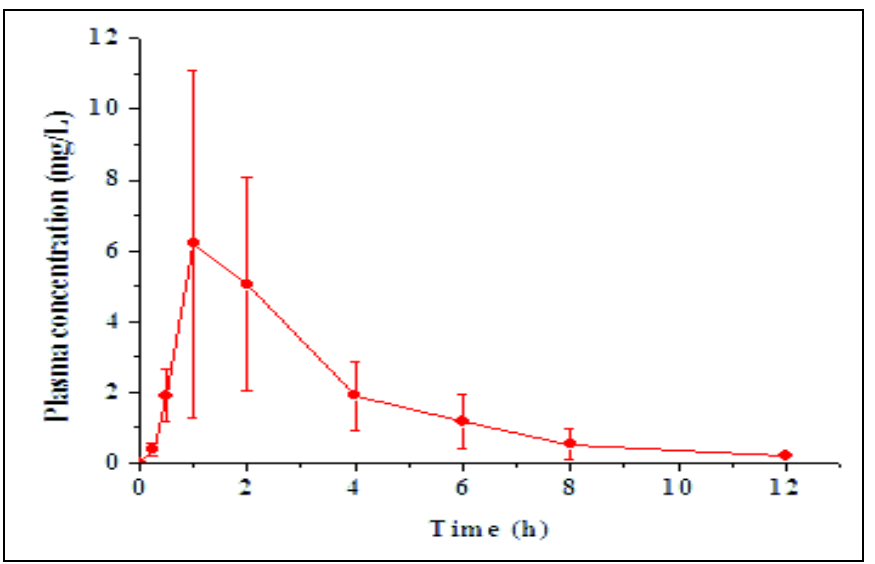

FIG. 2: THE PLASMA CONCENTRATION-TIME PROFILE OF ATC-MEs $(75 \mathrm{mg} / \mathrm{kg}, \mathrm{BW})($ mean $\pm \mathrm{SD}, \mathrm{n}=$ 6)
The oral pharmacokinetic parameters are given in Table 3. Time to achieve maximum concentration in plasma was $1.83 \pm 1.17 \mathrm{~h}\left(\mathrm{~T}_{\max }\right)$, the maximum peak concentration $\left(\mathrm{C}_{\max }\right.$ ) was $8.34 \pm 3.66 \mathrm{mg} / \mathrm{L}$, the elimination half-life $\left(\mathrm{T}_{1 / 2}\right)$ was $2.77 \pm 1.06 \mathrm{~h}$, area under the curve for concentration (AUC ${ }_{0-\infty}$ ) was $22.07 \pm 5.44 \mathrm{mg} \cdot \mathrm{h} \cdot \mathrm{L}^{-1}$, the mean residence time (MRT) was $3.85 \pm 1.12 \mathrm{~h}$.

TABLE 3 PHARMACOKINETIC PARAMETERS OF ATC-MEs $(75 \mathrm{mg} / \mathrm{kg}, \mathrm{BW})($ mean $\pm \mathrm{SD}, \mathrm{n}=6)$

\begin{tabular}{cc}
\hline Group & Micro-emulsion \\
\hline $\mathrm{Ke}\left(\mathrm{h}^{-1}\right)$ & $0.27 \pm 0.08$ \\
$\mathrm{~T}_{1 / 2}(\mathrm{~h})$ & $2.77 \pm 1.06$ \\
$\mathrm{~T}_{\text {max }}(\mathrm{h})$ & $1.83 \pm 1.17$ \\
$\mathrm{AUC}_{0-\infty}\left(\mathrm{mg} \cdot \mathrm{h} \cdot \mathrm{L}^{-1}\right)$ & $22.07 \pm 5.44$ \\
$\mathrm{AUMC}_{0-\infty}\left(\mathrm{mg} \cdot \mathrm{L}^{-1} \cdot \mathrm{h}^{2}\right)$ & $81.66 \pm 20.68$ \\
$\mathrm{C}_{\max }(\mathrm{mg} / \mathrm{L})$ & $8.34 \pm 3.66$ \\
$\mathrm{MRT}(\mathrm{h})$ & $3.85 \pm 1.12$ \\
\hline
\end{tabular}

The pharmacokinetics data of ATC-MEs after oral administration is few. Table 3 compared the oral absorbability of ATC-MEs to literature data on the oral absorbability of other ATC formulations. 
ATC in atorvastatin hydroxypropyl- $\beta$-cyclodextrin complex showed rapid absorption $\left(\mathrm{T}_{\max }=0.35\right)$ as compared to Lipitor ${ }^{\circledR}\left(\mathrm{T}_{\max }=0.5\right)$, Pure $\left(\mathrm{T}_{\max }=\right.$ 1.0) and ATC-MEs $\left(\mathrm{T}_{\max }=1.8\right)$. However, $\mathrm{C} \max$ for ATC-MEs (8341.1 $\pm 3658.1 \mathrm{ng} / \mathrm{ml}$ ) much higher than that for atorvastatin hydroxypropyl- $\beta$ - cyclodextrin complex, Lipitor ${ }^{\circledR}$ and Pure ATC $(1977.91 \pm 411.73 \mathrm{ng} / \mathrm{ml}, 1392.67 \pm 273.62$ and $526.87 \pm 93.60 \mathrm{ng} / \mathrm{ml}$ respectively). Similarly ATC-MEs had the greater area under the concentration time curve (AUC) in the four formulas (Table 4).

TABLE 4: COMPARISONS TO LITERATURE DATA ON THE ABSORPTION OF OTHER ATC FORMULATIONS DEVELOPED TO ENHANCE ATC GASTROINTESTINAL ABSORPTION

\begin{tabular}{ccccc}
\hline & Experiment & Literature 8 & Literature 8 & Literature 8 \\
\hline $\begin{array}{c}\text { Experimental animals } \\
\text { Administration dosage } \\
(\mathrm{mg} / \mathrm{kg})\end{array}$ & $\begin{array}{c}\text { Sprague-Dawley } \\
\text { rats }\end{array}$ & Sprague-Dawley rats & $\begin{array}{c}\text { Sprague-Dawley } \\
\text { rats }\end{array}$ & $\begin{array}{c}\text { Sprague-Dawley } \\
\text { rats }\end{array}$ \\
$\begin{array}{c}\text { Administration way } \\
\text { Drug dosage form }\end{array}$ & Oral & 25 & 25 & 25 \\
$\mathrm{C}_{\text {max }}(\mathrm{ng} / \mathrm{ml})$ & ATC -MEs & $\begin{array}{c}\text { Atorvastatin Hydroxypropyl- } \\
\beta \text {-cyclodextrin Complex }\end{array}$ & Lipitor ${ }^{\circledR}$ & Pure ATC \\
$\mathrm{T}_{1 / 2}(\mathrm{~h})$ & $8341.1 \pm 3658.1$ & $1977.91 \pm 411.73$ & $1392.67 \pm 273.62$ & $526.87 \pm 93.60$ \\
$\mathrm{~T}_{\text {max }}(\mathrm{h})$ & $2.77 \pm 1.06$ & $4.95 \pm 0.29$ & $4.75 \pm 0.23$ & $4.31 \pm 0.38$ \\
$\mathrm{AUC}_{0-\infty}(\mathrm{ng} \cdot \mathrm{h} / \mathrm{ml})$ & $1.83 \pm 1.17$ & $0.35 \pm 0.17$ & $0.5 \pm 0.26$ & $1.0 \pm 0.30$
\end{tabular}

The results may be ascribed to many factors: first, the different formulations might be the key factor, which micro-emulsion and hydroxypropyl- $\beta$ cyclodextrin complex both can enhance bioavailability. Second, the dosage in dosage of ATC-MEs is 3-fold than that of other formulations in the same administration way. Third, despite they are Sprague-Dawley rats, different environment can lead to individual difference.

Finally, the addition of internal standard solution in other literature may add to the whole imprecision and inaccuracy of the process. It cannot be correct for extraction losses of ATC in the protein precipitation and may provide a false sense in the assay. Few of the method are reported for ATCMEs determination in Sprague-Dawley rats. This study would show a new, simple and suitability method for different application.

CONCLUSION: ATC has high utilization in human health, so the emphasis of the research should be maximizing its effectiveness and reducing the amount of side effects. Hence, a method for the determination of ATC which is precise, reliable and occupies only very little laboratory workforce should be developed, i.e. our method. The currently available methods using the simple method of HPLC-UV are either consuming a large volume of plasma sample or adding internal standard that can increase imprecision and inaccuracy of the study, which render them tedious and improbable to handle easily.

On the other hand, the highly sensitive methods of LC-MS are of restricted accessibility to research laboratories. Our HPLC-UV detection method is considerably simple, time saving, reproducible and relatively sensitive. This method is suitable for complete pharmacokinetic analysis in small animals with possible utilization in ATC-MEs.

\section{REFERENCES:}

1. H. Lennernas, Clinical pharmacokinetics of atorvastatin, Clin Pharmacokinet, 2003; 42: 1141-1160.

2. A. Corsini, S. Bellosta, R. Baetta, R. Fumagalli, R. Paoletti, F. Bernini, New insights into the pharmacodynamic and pharmacokinetic properties of statins, Pharmacol Ther. 1999; 84: 413-428.

3. D.D. Cilla, L.R. Whitfield, D.M. Gibson, A.J. Sedman, E.L. Posvar, Multiple-dose pharmacokinetics, pharmacodynamics, and safety of atorvastatin, an inhibitor of HMG-CoA reductase, in healthy subjects, Clin Pharmacol Ther. 1996; 60: 687-695.

4. K. Kandhwal, S. Dey, S. Nazarudheen, R. Arora, S. Reyar, N.R. Thudi, T. Monif, M.K. Singh, S. Rao, Pharmacokinetics of a Fixed-Dose Combination of 
Atorvastatin and Metformin Extended Release versus Concurrent Administration of Individual Formulations: A Randomized, Open-Label, Two-Treatment, Two-Period, Two-Sequence, Single-Dose, Crossover, Bioequivalence Study, Clin Drug Investig 2011; 31: 853-863.

5. Y.M. Yin, F.D. Cui, J.S. Kim, M.K. Choi, B.C. Choi, S.J. Chung, C.K. Shim, D.D. Kim, Preparation, characterization and in vitro intestinal absorption of a dry emulsion formulation containing atorvastatin calcium, Drug Deliv 2009; 16: 30-36.

6. J.S. Kim, M.S. Kim, H.J. Park, S.J. Jin, S. Lee, S.J. Hwang, Physicochemical properties and oral bioavailability of amorphous atorvastatin hemi-calcium using spray-drying and SAS process, International Journal of Pharmaceutics 2008; 359: 211-219.

7. M. Anwar, M.H. Warsi, N. Mallick, S. Akhter, S. Gahoi, G.K. Jain, S. Talegaonkar, F.J. Ahmad, R.K. Khar, Enhanced bioavailability of nano-sized chitosan- atorvastatin conjugate after oral administration to rats, European Journal of Pharmaceutical Sciences 2011; 44: 241-249.

8. H.X. Lv, Z.H. Zhang, A.Y. Waddad, J.P. Zhou, Preparation, physicochemical characteristics and bioavailability studies of an atorvastatin hydroxypropyl-cyclodextrin complex, Pharmazie. 2012; 67: 46-53.

9. H.R. Shen, M.K. Zhong, Preparation and evaluation of self-microemulsifying drug delivery systems (SMEDDS) containing atorvastatin, Journal of Pharmacy and Pharmacology 2006; 58: 1183-1191.

10. F.N. Khan, M.H.G. Dehghan, Enhanced Bioavailability of Atorvastatin Calcium from Stabilized Gastric Resident Formulation, AAPS PharmSciTech 2011; 12: 1077-1086.

11. F.N. Khan, M.H.G. Dehghan, Enhanced Bioavailability and Dissolution of Atorvastatin Calcium from Floating Microcapsules using Minimum Additives, Sci Pharm 2012; 80: 215-228.

How to cite this article:

Hu L, Song W, Zhang H and Gu D: HPLC-UV method development for Atorvastatin calcium micro-emulsion determination in rat plasma and its application to elucidate pharmacokinetic behavior after oral administration to rats. Int J Pharm Sci Res 2013; 4(10): 3839-44. doi: 10.13040/IJPSR. 0975-8232.4(10).3839-44

All @ 2013 are reserved by International Journal of Pharmaceutical Sciences and Research. This Journal licensed under a Creative Commons Attribution-NonCommercial-ShareAlike 3.0 Unported License.

This article can be downloaded to ANDROID OS based mobile. Scan QR Code using Code/Bar Scanner from your mobile. (Scanners are available on Google Playstore) 